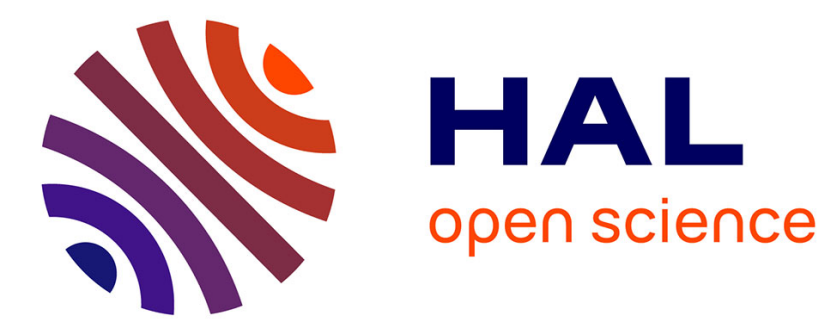

\title{
A CRYOGENICALLY STABLE SUPERCONDUCTING MAGNET
}

\author{
L. Lin, Z. Wang, H. Chen, Y. Han, Xiaojian Li
}

\section{To cite this version:}

L. Lin, Z. Wang, H. Chen, Y. Han, Xiaojian Li. A CRYOGENICALLY STABLE SUPERCONDUCTING MAGNET. Journal de Physique Colloques, 1984, 45 (C1), pp.C1-833-C1-836. 10.1051/jphyscol:19841170 . jpa-00223645

\section{HAL Id: jpa-00223645 https://hal.science/jpa-00223645}

Submitted on 1 Jan 1984

HAL is a multi-disciplinary open access archive for the deposit and dissemination of scientific research documents, whether they are published or not. The documents may come from teaching and research institutions in France or abroad, or from public or private research centers.
L'archive ouverte pluridisciplinaire HAL, est destinée au dépôt et à la diffusion de documents scientifiques de niveau recherche, publiés ou non, émanant des établissements d'enseignement et de recherche français ou étrangers, des laboratoires publics ou privés. 


\title{
A CRYOGENICALLY STABLE SUPERCONDUCTING MAGNET
}

\author{
L.Z. Lin, Z.K. Wang, H.S. Chen, Y.S. Han and X.L. Li \\ Institute of Electrical Engineering, Aoademia Sinica, Beiging, China
}

\begin{abstract}
Résumé - Pour un grand projet en cours en Chine, un aimant supraconducteur cryogéniquement stable de $35 \mathrm{~cm}$ de diamètre produisant un champ de $4 \mathrm{~T}$ en utilisant différentes configurations de conducteurs a été construit à l'Institut de Génie électrique de I'Académie des Sciences.
\end{abstract}

Abstract - For a large magnet project in China, a $35 \mathrm{~cm}$ diameter bore cryogenically stable superconducting model generating a magnetic field of $4 \mathrm{~T}$ using different conductor configuration was built by the Institute of Electrical Engineering of Academia Sinica.

\section{1 - INTRODUCTION}

This superconducting magnet program was stimulated by the possible need for a large coil for a detector. Based upon the experiment of a $10 \mathrm{~cm} / 4 \mathrm{~T}$ superconducting magnet /1/. a NbTi superconductor with a copper matrix of $\mathrm{Cu} / \mathrm{SC}$ ratio 10 and a size of 3.6 $x 7 \mathrm{~mm}^{2}$ was proposed. To determine the most economical manufacturing, three types of conductor were made by Baoji Institute of Non-Ferrous Metal Research: one monolithic conductor and two composite conductors. A $35 \mathrm{~cm} / 4 \mathrm{~T}$ superconducting magnet was built using these conductors in a pancake structure. It was of particular interest to compare the performance of the critical current and the stability behaviour of these conductors, the critical current $I$, the take-off current $I_{\text {, }}$, the recovery current $I_{n}$ and the current sharing behaviour of these conductors ${ }^{\circ}$ were determined at the Institute of Technical Physics of Nuclear Research Centre of Karlsruhe, FRG /2/.

The $35 \mathrm{~cm} / 4 \mathrm{~T}$ superconducting magnet was built to demonstrate the use of these conductors and their quantity production. This magnet will also provide informations needed for the design of a larger magnet with a bore about $1 \mathrm{~m}$ and a field of. $3.5 \mathrm{~T}$.

The calculations and the experiments of the field distribution and the iron magnetization when the superconducting magnet was surrounded by the iron yoke were studied. They will be introduced in another paper.

\section{2 - THE CONDUCTOR CONFIGURATIONS}

The main parameters of the conductor are given in the following: Size $3.6 \times 7 \mathrm{~mm}^{2}$; Filament diameter $70 \mu \mathrm{m}$; Number of filaments 432 ; Twist pitch $120 \mathrm{~mm} ; \mathrm{Cu} / \mathrm{SC}$ ratio 10 .

Fig. 1, a shows the schematic cross section of the monolithic conductor. There are grooves of $0.5 \mathrm{~mm}$ deep and $1 \mathrm{~mm}$ wide across both of the broad faces, which increase the surface area of the conductor exposed to the helium. The schematic cross sections of the two other composite conductors are also shown in Fig. 1. In case b, the superconductor soldered into the U-shaped copper strip has a size of $1.5 \times 2.8 \mathrm{~mm}^{2}$. 432 filaments of $70 \mu \mathrm{m}$ diameter are embedded in a copper matrix of $\mathrm{Cu} / \mathrm{SC}=1$ and are twisted with a pitch of $12 \mathrm{~cm}$. In case $c$, the U-shaped copper strip consists of three parts which are soldered together with the same superconductor applied by lead-tin solder. The size of conductors and the arrangement of grooves are the same as the monolithic conductor.

Fig. 2 shows the critical current $I_{c}$, the take-off current $I_{t . o}$, and the recovery 

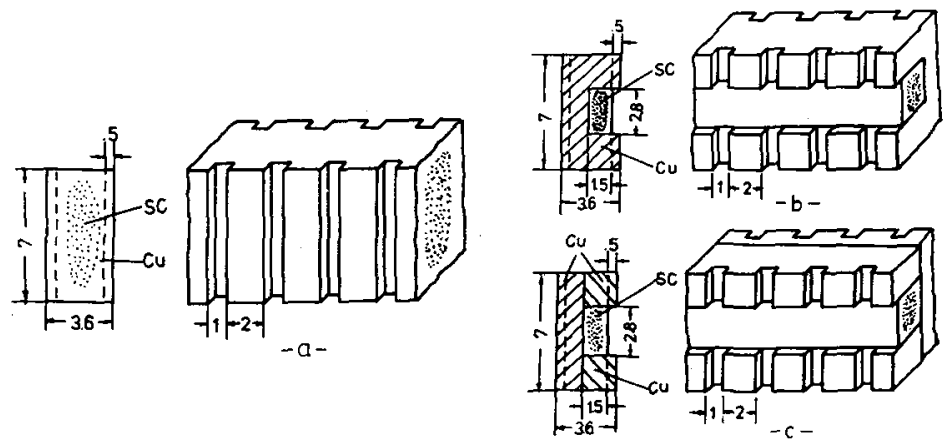

Fig. I - The schematic cross section of the three types of superconductors

current $I_{\text {f }}$ of the monolithic conductor in dependence on the magnetic field from $7 \mathrm{~T}$ to $10 \mathrm{~T}$. The critical current I was defined for a voltage drop of $0.2 \mu \mathrm{V}$ per cm of conductor length. The take-off current $I_{\text {. }}$ is that current in the current sharing regime, at which the superconducting stage ${ }^{\circ}$ reaks down completely by lack of cooling power or internal processes in the superconductor. The recovery current $I_{n}$ is the limit of current at which the superconducting stage is restored after an excursion into normal conductivity which was produced by a heat pulse of about $0.6 \mathrm{~J}$.

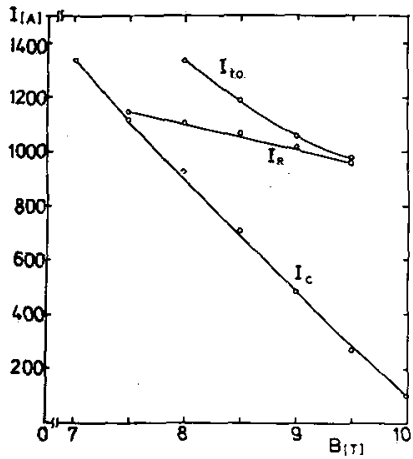

Fig. 2 - The characteristics of the monolithic conductor

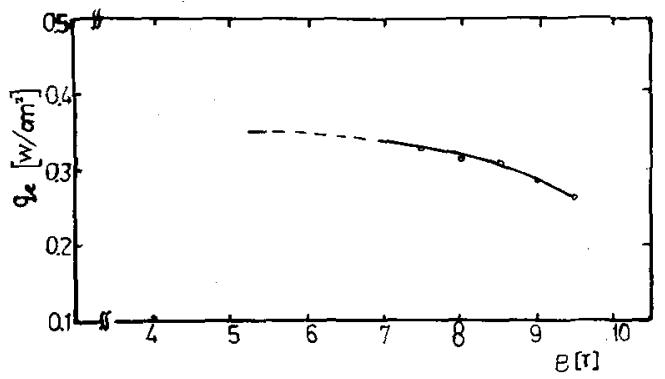

Fig. 3 - The effective heat rate $q_{e}$ versus the magnetic field $B$

The Maddock stability criterion /3/

$$
q_{e}=\frac{P(B) I^{2}}{A \cdot \eta \cdot P}
$$

is used as a measure of stability. $q_{e}$ is the effective heat flow rate, $P(B)$ is the resistivity of the Cu-stabilizer. A is the cross section of the stabilizer, $\eta$ is the liquid helium wetted fraction of the surface and $P$ is the perimeter of the conductor.

The effective heat flow rate $q_{\text {}}$ can be calculated if the current I is replaced by the recovery current $I_{n}$. Fig. 3 shows the calculated values of the effective heat flow rate $\mathrm{q}_{e}$ of the composite conductor in dependence on the magnetic field $B$.

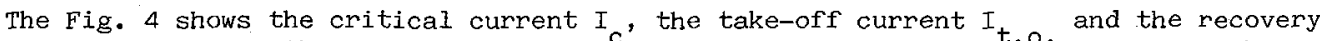
current I versus the magnetic field B for both soldered composite ${ }^{\circ}$ conductors. There is nearly ${ }^{r}$ no different in the performance compared with the monolithic conductor. 

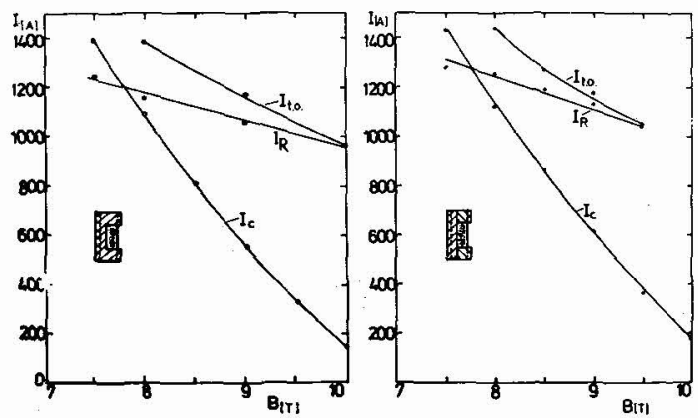

Fig. 4 - The characteristics of both soldered composite conductors

\section{3 - COIL CONSTRUCTION}

As Fig. 5 is shown, the coil consists of 18 double pancakes. The pancakes are separated by glass epoxy spacers allowing direct cooling by the liquid helium. Spacers between the pancakes are $2 \mathrm{~mm}$ thick. The joint between pancakes are on the outside of the winding. The resistance of each joint is less than $10^{-6} \Omega$ at $4.2 \mathrm{~K}$ when carrying of $1500 \mathrm{~A}$. The turns are insulated from each other by $0.25 \mathrm{~mm}$ thick polyester tape of the same width as the conductor. The coil is compressed heavily by the axial bolts.

The main parameters of the coil are given in the following:

$\begin{array}{lr}\text { Winding I.D. } & 35 \mathrm{~cm} \\ \text { Winding O.D. } & 62 \mathrm{~cm} \\ \text { Axial length of winding } & 33 \mathrm{~cm} \\ \text { Number of double pancakes } & 18 \\ \text { Number of turns } & 1188 \\ \text { Operating current } & 1500 \mathrm{~A} \\ \text { Central field } & 4 \mathrm{~T} \\ \text { Peak field } & 4.8 \mathrm{~T} \\ \text { Inductance } & 0.38 \mathrm{H} \\ \text { Stored energy } & 427.5 \mathrm{KJ} \\ \text { Overall current density } & 4000 \mathrm{~A} / \mathrm{cm}^{2} \\ \text { Conductor weight } & 344 \mathrm{~kg} \\ \text { Total weight } & 400 \mathrm{~kg}\end{array}$

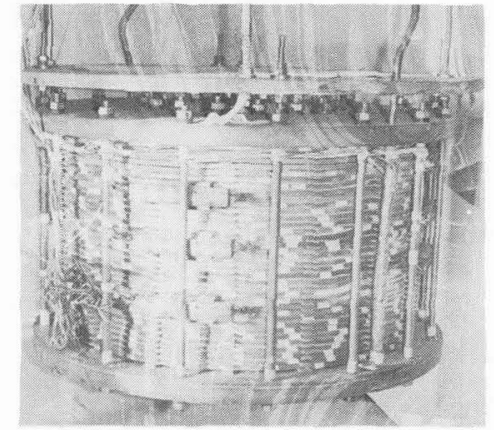

Fig. 5 - Overall view of the magnet

\section{4 - TEST AND PERFORMANCE}

The simplified diagram of the energizing and protective system of the magnet is shown in the Fig. 6. To energize the magnet, a power supply provides a $18 \mathrm{~V}$ maximum voltage and a current of $3000 \mathrm{~A}$.

The magnet is protected against sudden release of the magnetic stored energy (quench) by means of a parallel resistor $R$. When a resistive region is developed in the coil, the power supply is disconnected from the circuit, and the coil current is forced to flow through the external resistor. The external resistor $R=0.2 \Omega$ is then decided and the field decay time is $\tau=1.7 \mathrm{sec}$.

A compensation method is applied to detect the onset of quenching but to reject signals resulting from the flux jumps and small spurious transients. So that, an additional mutual inductor $M$ is used to compensate the EMF of the coil during the operating. 
During the first test, the normal conducting zone in the coil is observed when the current reached $1553 \mathrm{~A}$. At this value the peak field on the conductor is $5.05 \mathrm{~T}$ and the central field is $4.185 \mathrm{~T}$ (Fig. 7).

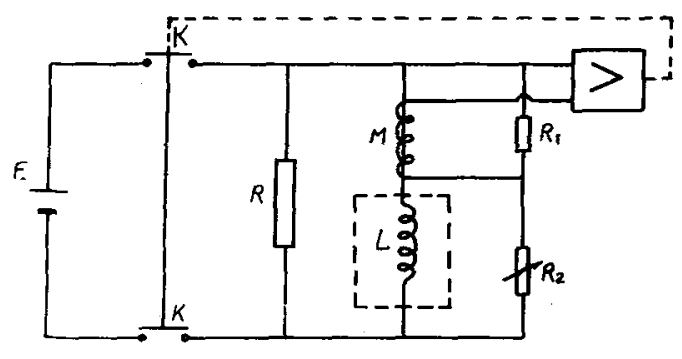

Fig. 6 - The simplified diagram of the energizing and protective system of the magnet

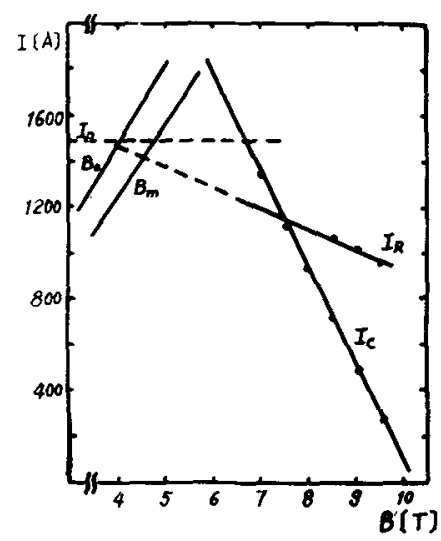

Fig.7 - The characteristics of the magnet

According to the short sample test, the effective heat flux that is about $0.35 \mathrm{~W} / \mathrm{cm}^{2}$ (Fig. 3) leads to an expected recovery current of approximately $1420 \mathrm{~A}$. although the recovery current $I_{r}$ is somewhat smaller than the operating current of $1500 \mathrm{~A}$, the disturbance in the ${ }^{r}$ coil does not have the high energy density which was applied during the experiment. As a matter of fact, the magnet has successfully been test to $1500 \mathrm{~A}$ which gave central field of $4 \mathrm{~T}$ without any sign of a normal region appeared despite the current being well in excess of $I_{r}$. The region of normality has appeared in the coil only when the operating current was raised to $1550 \mathrm{~A}$.

The other two experiments have shown that the normal conducting region has been observed and then propagated along the conductor when carrying current of $1546 \mathrm{~A}$ and of 1551 A respectively.

\section{5 - SUMMARY}

The experiments have shown that the magnet using these different conductor configurations in a pancake structure achieved its designed values successfully. The performance of these conductors are satisfactory and possible use for a $1 \mathrm{~m}$ bore superconducting magnet. Because of the high copper content there is an extended current sharing regime which offers a marginal safety in case of overcurrents. The large coil can be designed according to the behaviours of these conductors.

\section{$6-$ REFERENCES}

1). Lin, L.Z., et al, The Symposium of the Institute of Electrical Engineering, Academia Sinica, 3, (1980)

2) Turowski, P., Lin, L.Z., Acta Physica Temperaturae Humilis Sinica, 1, (1983)

3) Maddock, J.B., Cryogenics, 9, (1969) 